\title{
The effect of presemantic acoustic adaptation on semantic "satiation"
}

\author{
MAURA PILOTTI \\ City College and The College of Staten Island/CUNY, Staten Island, New York \\ and \\ JOHN S. ANTROBUS and MARTIN DUFF \\ City College/CUNY, New York, New York
}

\begin{abstract}
A decrement in the strength of the meaning of a word after rapid repetition of that word has been called "semantic satiation." This study asked whether this "satiation" might be produced by presemantic acoustic adaptation. Category words were utilized to prime the meaning of target words. The adaptation or "satiation" procedure, 30 rapid repetitions of the primes, was compared with a control condition of 3 repetitions. Participants listened to a series of prime words, each repeated by either the same speaker or many speakers, and then made semantic decisions on target words. When all the repetitions of a prime word are produced by the same speaker, presemantic and semantic repetitions are confounded. When the repetitions are produced by different speakers, presemantic acoustic repetition is abolished. A semantic decrement was detected with single-speaker, but not with multiple-speaker, repetitions of prime words. This study concluded that the semantic "satiation" observed here was a decrement in the activation level of semantic representations induced by presemantic acoustic adaptation.
\end{abstract}

A temporary decrement in the strength of the meaning of a word after rapid repetition of that word has been called semantic satiation. This study examines whether this "satiation" is produced by presemantic acoustic adaptation.

If a person repeats a word rapidly by saying it aloud (Bassett \& Warne, 1919; Fillenbaum, 1964; Lambert \& Jakobovits, 1960; Mason, 1941; L. Smith \& Klein, 1990; Titchener, 1915) or by writing or fixating it (Don \& Weld, 1924; Esposito \& Pelton, 1971; Severance \& Washburn, 1907), a temporary decrement in the meaning of that word is observed. This decrement has been attributed to a semantic adaptation process called semantic satiation.

In a related procedure, when a person listens to a rapidly repeated word, phonetic distortions that include meaningful words are found (Warren, 1961, 1968). With instructions that de-emphasize memory for words, reports that include nonwords are observed (Taylor \& Henning, 1963). These illusory distortions are called verbal transformations to distinguish them from semantic satiation. Similarly, the selective adaptation paradigm in speech perception has produced cases in which the massed repetition of a speech or speech-like sound, the adaptor, diminishes the listener's perception of that sound (Eimas \& Corbit, 1973; Samuel, 1986; Sawusch \& Mullenix, 1985; Sawusch \& Nusbaum, 1983; Sawusch \& Pisoni, 1976).

Special thanks are extended to Arti Itra for his contribution in devising the apparatus, to Raymond Klein, an anonymous reviewer, and Michael Masson for their helpful criticism, and to the participants of this study. Correspondence concerning this article should be addressed to M. Pilotti, Department of Psychology, The College of Staten Island of CUNY, 2800 Victory Boulevard, Staten Island, NY 10314 (e-mail: pilotti(apostbox.csi.cuny.edu).
To the extent that semantic satiation procedures, such as repeatedly writing, fixating, and speaking aloud, are accompanied by vocal and subvocal processes, they can be distinguished from acoustic adaptation procedures, such as Warren's $(1961,1968)$, primarily on the basis of what the researcher measures: semantic decrement in the former and perceptual changes in the latter. Indeed, Warren and Gregory (1958) suggested that repeating a word aloud also involves verbal transformations. Reisberg, Smith, Baxter, and Sonenshine (1989) observed these transformations in the subvocalization portion of an auditory imagery task and significantly reduced them with a procedure that minimized subvocalizations.

The present experiment first examines whether a semantic decrement (i.e., repetition effect) occurs with the Warren procedure, which involves auditory word repetition with one speaker. Although Warren (1968) reported that his single-speaker procedure produced no semantic satiation, he did not, in fact, test for the effect. Neely (1977) and L. C. Smith (1984) argued that evidence for semantic decrement requires explicit measurement of semantic processing. In the present experiment, a semantic decision task, which was first applied to the study of semantic satiation by L. Smith and Klein (1990), is used. After being exposed to a repeated category name, for example, FLOWER, participants must decide whether two targets belong to the same category, rose-tulip, regardless of the repeated category.

The category name heard before the target pair, the prime, is repeated either 3 or 30 times. It is assumed that the first few repetitions of a prime word activate a subset of features, which represent the meaning of the prime 
(Tabossi, Colombo, \& Job, 1987). The target word pair is selected so that many of the semantic features of the targets are the same as those of the prime. It is assumed that the prior activation of the features of the prime reduces the latency of the activation of the targets' semantic information. Consequently, any semantic decision that is dependent on the meaning of the targets is facilitated. This saving of response latencies is an index of the activation of the targets' semantic representation by the prime, and thus it represents an estimate of the degree of semantic activation of the category name itself $(\mathrm{McNa}-$ mara, 1992). Thirty repetitions of the prime are expected to diminish (L. Smith \& Klein, 1990) or possibly eliminate (Titchener, 1915) this priming effect.

The experiment then examines the locus of the repetition effect. This examination is based on the assumption that speech perception and comprehension entail the activation of a complex series of increasingly abstract representations of the acoustic signal (Pisoni \& Sawusch, 1975 ), leading to the identification of words and the activation of their meaning. For the purpose of this study, these levels may be roughly separated into semantic (Hinton \& Shallice, 1991) and presemantic, and the latter into acoustic and phonetic (Pisoni, 1973; Sawusch, 1977). It follows that one can speak of adaptation effects in the same way. If presemantic acoustic adaptation occurs with auditory repetition, the information forwarded to the semantic level will be weakened or possibly degraded. The weakened input will increase the time required for the semantic analysis to activate the meaning of this input. This increased latency cannot, however, be called semantic "satiation." A repetition-induced decrement in semantic activation can be attributed to semantic "satiation" (i.e., adaptation) only if there is no adaptation of any of the preceding stages of speech perception.

It is suggested that the early acoustic portion of presemantic processing might be the primary locus of the adaptation effect associated with massed word repetition. A way of testing its contribution to semantic "satiation" is to eliminate the adaptation due to acoustic repetition. Adaptation at an early acoustic level of processing can be eliminated by using different speakers to represent the string of repeated words. Mass repetition of a prime word by a succession of different speakers eliminates most of the acoustic repetition that characterizes massed repetition by the same speaker, while preserving phonetic and semantic repetition (see Schacter \& Church, 1992, and Sawusch, 1977, for qualifications). If the repetition effect obtained with single-speaker repetitions of a given prime is eliminated in the multiple-speaker condition, then adaptation at the acoustic level of analysis is likely to be responsible for what has been called "semantic satiation." Alternatively, if the repetition effect is unaltered by the speaker manipulation, then acoustic adaptation is not the locus of the effect. If the reduced spectral overlap of successive multiple-speaker repetitions, however, simply diminishes the magnitude of the repetition effect, adaptation must occur at multiple levels (acoustic, phonetic, and perhaps semantic). Sawusch's (1977) ac- count of adaptation in speech perception partially supports the latter hypothesis by suggesting that adaptation occurs at both the acoustic and the phonetic levels. ${ }^{1}$

In summary, the purpose of this experiment is twofold: first, to determine whether semantic decrement occurs with 30 relative to 3 rapid acoustic repetitions of a prime, and second, to assess whether the decrement, if any, involves presemantic acoustic adaptation. The choices of 30 repetitions for the adaptation condition and 3 for the control condition are borrowed from the work of L. Smith and Klein (1990). The 3-repetition format is used to maximize the facilitatory impact that prior exposure to a word may have on subsequent processing of that word, and thus obtain a suitable comparison condition for the 30-repetition format. Each trial consists of either 3 or 30 repetitions of a prime followed by a single target pair. Relevant studies of the semantic "satiation" effect (L. C. Smith, $1984 ;$ L. Smith \& Klein, 1990) demonstrated that massed repetition of category names-for example, FLOWERdiminishes their ability to activate the meaning of targets that are exemplars of such categories-for example, rosetulip. These studies, however, also combined multiple "satiation" procedures (visual, acoustic, and motorvocal) and utilized them in parallel, thus making the task of isolating the source of the repetition effect unattainable. The present experiment uses a revised version of the L. Smith and Klein (1990) procedure that confines the "satiation" procedure to acoustic repetition. Stimuli are auditorily presented, and the repetition rate is fast so as to diminish the likelihood of subvocalizations. In the L. Smith and Klein procedure, attention to the repetition sequence is obtained by saying aloud each repetition of a printed category name. The category name is simply not used in responding to a target pair. Even if massed repetition abolishes the activation due to automatic processing, attention to the repetition sequence allows the category to benefit from some residual activation (L. Smith $\&$ Klein, 1990). Therefore, the category continues to facilitate the response to its exemplars. In the present experiment, to preserve this residual activation of the category name in primed trials-as in FLOWER: rose-tulipparticipants are instructed to attend to each repetition.

To obtain a measure of semantic decrement, the present experiment employs primed trials, in which a category is followed by two of its dominant exemplars-FLOWER: rose-tulip - and unprimed trials, in which a category is followed by two dominant exemplars of another category-FRUIT: rose-tulip. Savings in response latency in primed trials relative to unprimed trials provide an estimate of the degree of semantic activation of the category names. A reduction of these savings following mass repetition is a measure of semantic decrement. To compel participants to wait for both targets to be heard before producing a response, filler trials in which a member of the repeated category is paired with a nonmemberFLOWER: daisy-beer - are employed. To ensure that responses in primed and unprimed trials are based on categorical membership rather than semantic association, the experiment utilizes filler trials in which the two tar- 
gets are semantically related so as to form a compound noun; however, neither is a member of the same category or a member of the repeated category-FLOWER: bullethole. Lastly, there are filler trials in which targets are members of different categories and neither target is a member of the repeated category-FLOWER: stereobronze. On the basis of L. Smith and Klein's (1990, p. 854) findings, in all the filler trials, the rejection of target pairs is not expected to be influenced by the repetition treatment.

\section{METHOD}

\section{Subjects}

One-hundred and twenty undergraduate students from the college population participated as subjects in the experiment for academic credit. They reported no history of speech or hearing disorder and English was their first language. Two additional participants were discarded for failure to meet the $90 \%$ correct requirement in the practice session

\section{Materials and Design}

Thirty category names, chosen as primes (e.g., FLOWER), were selected from the work of Battig and Motague ( I969), L. C. Smith (1984), and L. Smith and Klein (1990) and adapted wherever deemed necessary. For each category name, five target pairs were selected, thus creating five category-target relations and a total of $150(30 \times 5)$ trials (see Appendix A). There were two category-target relations in which the targets belonged to the same category and therefore required a YES response:

1. Both targets belonged to the same category as the repeated category-FLOWER: rose-tulip (primed trials).

2. Both targets belonged to a different category-FLOWER: shrimplobster (unprimed trials).

The remaining relations required a No response because both targets did not share the same category (filler trials):

3. One target belonged to the same category as the repeated category-FLOWER: daisy-beer.

4. Both targets were not members of the repeated categoryFLOWER: stereo-bronze.

5. Targets were semantically associated so as to create a compound noun, but were not members of the repeated categoryFLOWER: bullet-hole.

The 30 primed trials-FLOWER: rose-tulip-were obtained by asking independent participants to generate exemplars for each of the category names and then selecting the two exemplars most frequently generated (dominant members). The 30 unprimed trials in which both targets were members of a category different from the repeated category-FLOWER: shrimp-lobster and FRUIT: rosetulip-were obtained by pairing these exemplars with a category that did not include them. The filler trials in which one of the targets was a member of the repeated category-FLOWER: daisybeer - were obtained by selecting a word generated as a member of the repeated category and another produced as a member of another category (30 trials). The remaining filler trials were either pairs of unrelated words selected from the remaining pool of words of the generation task ( 30 trials), or two words that formed a compound noun ( 30 trials). Ratings of the extent to which a target in a pair fitted the idea or image of the meaning of the category with which it was paired were obtained to further verify either the presence or the absence of categorical membership in each of the experimental trials (Mervis \& Rosch, 1981; Rosch, 1975; E. E. Smith \& Medin. 1981). The same procedure was utilized to acquire the 18 category names and 90 target pairs $(18 \times 5)$, for the practice session.
The 150 experimental trials were arranged in sets of 30 trials each. A Latin square design, utilized to counterbalance categorytarget relations, produced 30 sets. Each set contained six trials per category-target relation. The counterbalancing of primed and unprimed trials produced 10 sets so that when six target pairs were used in the primed trials of a set-for example, FLOWER: rose-tulip-in another set, the same pairs comprised the unprimed trials-FRUIr: rose-tulip. The counterbalancing of filler trials originated three versions of each set $(10 \times 3)$. When in one version of a set, six categories were combined with pairs in which one of the targets was a member of the category-for example, METAL: brass-thunder-in the other version, the same categories were matched with pairs of unrelated words-METAL: lettuce-brandy - and in the third version, with compound nouns-METAL: feather-bed. Within a set, for each of the six category-target relations, three trials were selected for the 3 -repetition condition and three were selected for the 30-repetition condition. The 3 - and 30-repetition trials were reversed to create 30 additional sets. Therefore, in each set, half of the prime categories were repeated 3 times, and half, 30 times.

Two versions of each set were constructed: a single- and a multiplespeaker version for a total of 120 sets. In each single-speaker condition, a speaker randomly selected from a database of 10 speakers uttered all the repetitions of the category words and the targets. In the multiple-speaker condition, the speaker's voice for the 3 repetitions of a prime was selected randomly from the same database, and each repetition was uttered by a different speaker. Each of the 30 repetitions of a prime was quasi-randomly selected from the same database such that each speaker was chosen 3 separate times but never consecutively. Target words were always produced by the speaker who had uttered the last repetition of the preceding prime.

The 60 sets of a speaker condition were organized in blocks of 4 . The 4 sets in a block were selected so that any 2 sets contained the same prime-target relations except that the 3 and 30 repetitions of the category names were inverted. A Latin square was utilized to counterbalance the category-target relations between pairs of sets, so that when in two sets a category name was followed by its exemplars-FLOWER: rose-tulip (primed trial)-in the other two sets, these targets were preceded by another category name--FRUIT: rose-tulip (unprimed trial). Similarly, when in two sets a category name-for example, METAL--was followed by a target pair comprising a member and a nonmember of the category-say, brassthunder-in the other two sets it was followed by either two unrelated words, lettuce-brandy, or a compound noun, feather-bed. Randomization was utilized to determine the order in which the four sets of a block were presented with the requirement that no contiguous sets contain the same category-target relations.

The experimental design was a $5 \times 2 \times 2$ mixed factorial model: category-target relation ( 5 types: within subjects) $\times$ number of repetitions ( 3 vs. 30: within subjects) $\times$ speaker (single vs. multiple: between subjects).

\section{Speech Recording and Apparatus}

Ten speakers produced the stimuli for both single- and multiplespeaker conditions. Four additional speakers were utilized in the practice session. The stimuli, category names and targets, were recorded, low-pass filtered at $4.8 \mathrm{kHz}$, and digitized at an $11-\mathrm{kHz}$ sampling rate with a 16 -bit analog-to-digital converter equipped with antialiasing filters and installed on an IBM-compatible 486-66 personal computer. A file was created for each stimulus by using a signal processing package. Two independent participants identified each of the recorded stimuli and rated its clarity on a scale from $1=$ very unclear to $5=$ very clear. Stimuli that were incorrectly identified and/or received a rating below or equal to 3 by either rater were rerecorded and retested. The average duration of a file containing a category name was $.69 \mathrm{sec}$. The average duration of a file containing a target pair was as follows: pairs that contained two ex- 
emplars of a given category (primed and unprimed trials) = $1.42 \mathrm{sec}$, pairs that contained a member of the repeated category $=$ $1.49 \mathrm{sec}$, unrelated pairs $=1.53 \mathrm{sec}$, and compound nouns $=$ $1.40 \mathrm{sec}$. The members of a target pair were separated by a $30-\mathrm{msec}$ silent interval. The presentation of the speech tokens and the recording of the subjects' latencies were accomplished by using the apparatus described above to which a custom-made program was added. Stimuli filtered at $4.8 \mathrm{kHz}$ were presented over Koss Professional HV/1A headphones at $75 \mathrm{~dB}$.

\section{Procedure}

The subjects were asked to listen attentively to each repetition of a category name and then to make a category-matching decision on the subsequent target pair. To familiarize subjects with the apparatus and ensure their understanding of the task, a practice session was administered until 90\% accuracy was reached on two consecutive sets, each containing 18 trials with feedback. After four sets, subjects who did not achieve the $90 \%$ correct requirement were disqualified. Prior to the administration of the experimental treatments, the instructions were repeated and the examples of the practice session discussed.

Subjects were randomly assigned to either the single- or the multiple-speaker condition and were given a block of four sets of trials. An interval of 2 min was introduced between consecutive sets in order to allow the experimenter to run the next set and to break the monotony of the task. The order in which the trials were presented in a set was randomized separately for each subject. Each trial consisted of a $300-\mathrm{msec}, 1000-\mathrm{Hz}$ tone followed by a category name repeated either 3 or 30 times, with a 30 -msec interval between repetitions. A 300 -msec silent interval signaled the upcoming of a target pair. Manual responses to one of the two keys of an external device, appropriately labeled as YES and NO, started the next trial. If no response occurred within $3 \mathrm{sec}$, however, the next trial began. Response latencies were computed from the onset of each target pair.

\section{RESULTS AND DISCUSSION}

Response latencies for correct responses, the main dependent variable, were logarithmically transformed to improve the symmetry of the data distribution (Kirk, 1968). No outliers were removed. For each participant, mean response latencies for correct responses and mean percentages of errors were calculated over each of the stimulus conditions. Table 1 presents the mean latencies and standard deviations for correct responses along with the mean percent correct responses as a function of number of repetitions, speaker, and category-target relation (see Appendix B for log mean latencies and standard deviations). An alpha level of .05 was utilized in the following analyses. The test of the presemantic acoustic adaptation hypothesis was conducted in sequential steps.

\section{The Effect of Mass Acoustic Repetition on Semantic Priming}

The first purpose of this study was to determine whether rapid auditory repetition by the same speaker could produce an apparent semantic satiation effect. Semantic priming in the 3-repetition condition provided the reference point for measuring any decrement due to massed repetition of a category word. Semantic priming is an estimate of semantic activation of a category name. In primed trials-FLOWER: rose-tulip-response latencies reflect the ability of the category name to prime its exemplars. In unprimed trials-FRUIT: rose-tulip-response latencies display baseline performance. Therefore, when the judg-

Table 1

Mean Response Latencies (in Milliseconds), Standard Deviations, and Mean Percentage Accuracy as a Function of Number of Repetitions (3 or 30), Prime-Target Relation, and Speaker

\begin{tabular}{|c|c|c|c|c|c|c|c|}
\hline \multirow[b]{3}{*}{ Decision } & \multirow{3}{*}{$\begin{array}{l}\text { Prime-Target } \\
\text { Relation }\end{array}$} & \multicolumn{4}{|c|}{ Latency } & & \\
\hline & & \multicolumn{2}{|c|}{3} & \multicolumn{2}{|c|}{30} & \multicolumn{2}{|c|}{$\%$ Accuracy } \\
\hline & & $M$ & $S D$ & $M$ & $S D$ & 3 & 30 \\
\hline \multicolumn{8}{|c|}{ Single-Speaker Condition } \\
\hline Yes & $\begin{array}{l}\text { Both members } \\
\text { FLOWER: rose-tulip }\end{array}$ & 1,498 & 195 & 1,546 & 212 & 95.97 & 96.25 \\
\hline Yes & $\begin{array}{l}\text { No member } \\
\text { FLOWER: shrimp-lobster }\end{array}$ & 1,554 & 196 & 1,565 & 197 & 94.58 & 95.28 \\
\hline No & $\begin{array}{l}\text { One member } \\
\text { FLOWER: daisy-beer }\end{array}$ & 1,720 & 201 & 1,709 & 203 & 99.03 & 99.44 \\
\hline No & $\begin{array}{l}\text { No member } \\
\text { FLOWER: stereo-bronze }\end{array}$ & 1,770 & 203 & 1,766 & 207 & 97.36 & 98.20 \\
\hline No & $\begin{array}{l}\text { No member associated } \\
\text { FLOWER: bullet-hole }\end{array}$ & 1,714 & 213 & 1,702 & 214 & 95.83 & 96.25 \\
\hline \multicolumn{8}{|c|}{ Multiple-Speaker Condition } \\
\hline Yes & $\begin{array}{l}\text { Both members } \\
\text { FLOWER: rose-tulip }\end{array}$ & 1,551 & 152 & 1,555 & 136 & 96.67 & 98.06 \\
\hline Yes & $\begin{array}{l}\text { No member } \\
\text { FLOWER: shrimp-lobster }\end{array}$ & 1,621 & 158 & 1,614 & 143 & 94.86 & 95.56 \\
\hline No & $\begin{array}{l}\text { One member } \\
\text { FLOWER: daisy-beer }\end{array}$ & 1,773 & 140 & 1,768 & 126 & 96.67 & 98.89 \\
\hline No & $\begin{array}{l}\text { No member } \\
\text { FLowER: sterea-bronze }\end{array}$ & 1,831 & 133 & 1,806 & 143 & 95.97 & 98.61 \\
\hline No & $\begin{array}{l}\text { No member associated } \\
\text { FLOWER: bullet-hole }\end{array}$ & 1,765 & 155 & 1,739 & 153 & 95.70 & 96.42 \\
\hline
\end{tabular}


ment that two targets belong to the same category is facilitated by prior exposure to three repetitions of that category name, the difference in response latency is named semantic priming and regarded as a measure of the activation of the category name's meaning. A reduction of this semantic priming effect following massed acoustic repetition of the category name is considered as evidence that the semantic activation of the category name has been weakened by massed repetition.

A $2 \times 2$ analysis of variance (ANOVA) was conducted on the response latencies of the primed and unprimed trials, with category-target relation and number of repetitions as factors. This analysis displayed a main effect of number of repetitions $\left[F(1,59)=11.92, M S_{\mathrm{e}}=.0003\right.$, $p=.001]$, a main effect of category-target relation $\left[F(1,59)=19.72, M S_{\mathrm{e}}=.0003, p=.0001\right]$, and a significant interaction $\left[F(1,59)=5.80, M S_{\mathrm{e}}=.0003, p=.019\right]$. With 3 repetitions of category names, response latencies in primed trials-FLOWER: rose-tulip-were $56 \mathrm{msec}$ faster than those in unprimed trials-FRUIT: rose-tulip $[t(59)=6.03, S E=.003, p=.0001]$. The repeated categories clearly activated their exemplar pairs. With 30 repetitions, the 19-msec saving in response latency was not significant $(t=1.59)$. Massed acoustic repetition had substantially weakened the ability of the repeated categories to prime their members.

\section{The Effect of Mass Multiple-Speaker Repetition on Semantic Priming}

As in the single-speaker condition, the presemantic acoustic adaptation hypothesis predicted that 3 repetitions of a category name, say, FLOWER, would produce a saving in response latency. Massed multiple-speaker repetition, however, would not reduce or abolish this saving. The preceding $2 \times 2$ ANOVA was conducted on the response latencies of the prime and unprimed trials in the multiple-speaker condition. Only a main effect of categorytarget relation $\left[F(1,59)=34.72, M S_{\mathrm{e}}=.0003, p=.0001\right]$ was observed (the other $F \mathbf{s}<1$ ). Response latencies were, on the average, $65 \mathrm{msec}$ faster in primed trials-FLOWER: rose-tulip-than in unprimed trials-FRurr: rose-tulipregardless of the number of repetitions of the category name. Consistent with the conclusion that the ability of the category name to prime its exemplars had not significantly changed in the switch from 3 to 30 repetitions, the priming scores (unprimed trials minus primed trials) of the 3 -repetition condition were not significantly different from those of the 30-repetition condition $[t(59)=.62]$. This pattern of results supported the primary prediction of the presemantic acoustic adaptation hypothesis.

\section{The Effect of Mass Repetition on Filler trials}

The hypothesis that semantic decrement is dependent on acoustic massed repetition predicted that no repetition effect would be observed in trials in which both targets did not share a portion of the semantic representation of the repeated category. Although there were filler trials in which one of the targets was a member of the category, L. Smith and Klein's (1990) findings showed that both tar- gets need to belong to the repeated category for a repetition effect to be observed, A $2 \times 2 \times 3$ ANOVA was conducted on the response latencies of all the filler trials, with number of repetitions, speaker, and category-target relation as factors. Main effects were found only for categorytarget relation $\left[F(2,236)=35.27, M S_{\mathrm{e}}=.0005, p=\right.$ $.0001]$ and number of repetitions $\left[F(1,118)=8.89, M S_{\mathrm{e}}=\right.$ $.0003, p=.003$ ] . Of special interest was the main effect of number of repetitions, which showed that 3 repetitions produced, on the average, longer response latencies than did 30.

\section{The Effect of Mass Repetition and Multiple-Speaker Repetition on Semantic Priming in Filler Trials}

L. Smith and Klein's (1990) findings suggested that in filler trials in which one target was a member of the repeated category-FLOWER: daisy-beer-the category name was not sufficiently strong to prime one of its exemplars. To assess whether this conclusion could be generalized to the present experiment, the response latencies of these trials were combined with those of trials in which both targets were not members of the category-for example, FLOWER: stereo-bronze. The latter were assumed to display baseline performance. A $2 \times 2 \times 2$ ANOVA was conducted, with category-target relation, number of repetitions, and speaker as factors. The results displayed main effects for speaker $\left[F(1,118)=4.19, M S_{\mathrm{e}}=.01, p=\right.$ $.043]$, category-target relation $\left[F(1,118)=38.29, M S_{\mathrm{e}}=\right.$ $.0005, p=.0001]$, and number of repetitions $[F(1,118)=$ $\left.4.28, M S_{\mathrm{e}}=.0003, p=.041\right]$. Response latencies were, on the average, $50 \mathrm{msec}$ faster in trials in which one target was a member of the category than in trials in which both targets were members of other categories. This semantic priming effect was insensitive to mass repetition, either acoustic or multiple speaker.

In primed trials, massed acoustic repetition disrupted the ability of the repeated category to prime both targets. No equivalent disruption of semantic priming was found in filler trials in which only one target was a member of the repeated category. There is no reason to assume that massed acoustic repetition disrupted the semantic activation of two members of the repeated category but did not impair the activation of one member. In these filler trials, the stability of semantic priming was probably a spurious effect of the decision process. Following massed acoustic repetition, the reduced activation level of the target that was a member of the repeated category might have made this target less likely to share the same category with the other target. Then the rejection of the pair would have been facilitated relative to the baseline condition in which both targets did not belong to the repeated category.

\section{Accuracy and the Effect of Mass Repetition}

The preceding analyses were repeated on the accuracy data. The $2 \times 2$ ANOVA on the mean percent correct responses of the primed and unprimed trials produced, in the multiple-speaker condition, a main effect of category- 
target relation $\left[F(1,59)=9.95, M S_{\mathrm{e}}=27.95, p=.003\right]$. Accuracy was significantly higher in the primed than in the unprimed trials. Although not significant, a trend in the same direction was observed in the single-speaker condition $\left[F(1,59)=3.36, M S_{\mathrm{e}}=23.01, p=.061\right]$. The $2 \times 2 \times 3$ ANOVA on the accuracy of filler trials showed a main effect of number of repetitions $[F(1,118)=9.87$, $\left.M S_{\mathrm{e}}=26.63, p=.002\right]$ and a main effect of categorytarget relation $\left[F(2,236)=9.36, M S_{\mathrm{e}}=39.28, p=\right.$ $.0001]$. Accuracy was higher in the 30 -repetition condition than in the 3-repetition condition. Independently of the number of repetitions, the filler trials in which one target word was a member of the repeated categoryFLOWER: daisy-beer-produced, on the average, the highest level of accuracy. The latter finding showed that, contrary to the results of L. Smith and Klein (1990), the diminished accuracy of the unprimed trials - FRUIT: rosetulip - did not represent a tendency to respond to the category-target relationship rather than to the two targets as specified by the instructions.

\section{GENERAL DISCUSSION}

Listening to acoustically identical repetitions of a prime word produced semantic satiation in trials in which prime and target shared a common set of semantic features. Listening to acoustically different repetitions of the same prime did not. These findings do not support the assumption that the decrement in semantic activation is one of semantic "satiation." On the contrary, they suggest that semantic decrement with acoustically uniform repetitions of a prime word is primarily due to adaptation at the early acoustic stages of speech processing. This adaptation then disrupts the operations at the subsequent stages of processing up to semantic activation.

In agreement with the suggestion of Esposito and Pelton (1971), one may hypothesize that this adaptation produces the activation of alternative phonetic representations (verbal transformations) and, as a by-product, the activation of their corresponding semantic representations. The semantic representation(s) originally activated by exposure to the acoustic stimulus are now in conflict with newly activated representations. Interference related to the coexistence of these multiple semantic representations then produces semantic decrement. One may also hypothesize that this early adaptation simply weakens semantic activation. The evidence obtained, however, does not permit us to attribute the semantic decrement called semantic "satiation" to either mere lack of activation or interference. These processes will have to be the object of future investigation to determine their role in producing the once-labeled "semantic satiation" effect.

The present findings do not imply that the absence of acoustic adaptation would eliminate the effect of massed repetition in the multiple satiation procedure employed by L. Smith and Klein (1990). It is reasonable to hypothesize that the concurrent effect of the remaining repetition forms, such as visual and motor-vocal, would pro- duce semantic "satiation." The present findings, however, indicate that, in these procedures, semantic "satiation" is likely to be the product of a multimodal presemantic adaptation.

\section{REFERENCES}

BASSETT, M. F., \& WARNE, C. J. (1919). On the lapse of verbal meaning with repetition. American Journal of Psychology, 30, 415-418.

BatTig, W. F., \& Motague, W. E. (1969). Category norms for verbal items in 56 categories: A replication and extension of the Connecticut category norms. Journal of Experimental Psychology Monographs, 80( 3, Pt. 2)

Don, V. J., \& WELD, H. P. (1924). Lapse of meaning with visual fixation. American Journal of Psychology, 35, 446-450.

EIMAS, P. D., \& CORBIT, J. (1973). Selective adaptation of linguistic features detectors. Cognitive Psychology, 4, 99-109.

Esposito, N. J., \& Pelton, L. H. (1971). Review of the measurement of semantic satiation. Psychological Bulletin, 75, 330-346.

Fillendaum, S. (1964). Semantic satiation and decision latency. Journal of Experimental Psychology, 68, 240-244.

Hinton, G. E., \& Shallice, T. (1991). Lesioning an attractor network: Investigations of acquired dyslexia. Psychological Review, 98. 74-95.

KIRK, R. E. (1968). Experimental design: Procedures for the behavioral sciences. Belmont, CA: Brooks/Cole.

LAMBERT, W. E., \& JAKoBovits, L. A. (1960). Verbal satiation and changes in intensity of meaning. Journal of Experimental Psychology, 60, 376-383.

MASON, M. (1941). Changes in the galvanic skin response accompanying reports of changes in meaning during oral repetition. Journal of General Psychology, 25, 353-401.

MCNamaRa, T. P. (1992). Theories of priming: I. Associative distance and lag. Journal of Experimental Psvchology: Learning, Memory, \& Cognition, 18, 1173-1190.

Mervis, C. B., \& Rosch, E. (1981). Categorization of natural objects. Annual Review of Psychologv, 32, 89-115.

NeELy, J. H. (1977). The effects of visual and verbal satiation on a lexical decision task. American Journal of Psychology: General, 106. 226-254

PISONI, D. B. (1973). Auditory and phonetic memory codes in the discrimination of consonants and vowel. Perception \& Psychophysics, 13, 253-260.

Pisoni, D. B., \& Sawusch, J. R. (1975). Some stages of processing in speech perception. In A. Cohen \& S. G. Nooteboom (Eds.), Structure and process in speech perception. New York: Springer-Verlag.

Reisberg, D., Smith, J. D., Baxter, D. A., \& Sonenshine, M. (1989). "Enacted" auditory images are ambiguous: "Pure" auditory images are not. Quarterly Journal of Experimental Psychology, 41 A, 619-641.

Rosch, E. (1975). Cognitive representations of semantic categories Joumal of Experimental Psychology: General, 104, 192-233.

SAMUEL, A. G. (1986). Red herring detectors and speech perception: In defense of selective adaptation. Cognitive Psychology, 18, 452-499.

SAwusch, J. R. (1977). Peripheral and central processes in selective adaptation of place of articulation in stop consonants. Journal of the Acoustical Society of America, 62, 738-750.

SAWUSCH, J. R., \& MULLENIX, J. W. (1985). When selective adaptation and contrast effects are distinct: A reply to Diehl, Kluender, and Parker. Journal of Experimental Psychology: Human Perception \& Performance, 11, 242-250.

Sawusch, J. R., \& Nusbaum, H. C. (1983). Auditory and phonetic processes in place perception for stops. Perception \& Psychophysics, 34 560-568.

SAwusch, J. R., \& Pisoni, D. B. (1976). Response organization in selective adaptation to speech sounds. Perception \& Psichophvsics, 20. 413-418.

Schacter, D., \& Church, B. A. (1992). Auditory priming: Implicit and explicit memory for words and voices. Journal of Experimental Psychology: Learning. Memory, \& Cognition, 18, 915-930.

Sfyerance, E., \& Washburi, M. F. (1907). The loss of associative 
power in words after long fixation. American Journal of Psychology, 18, $182-186$.

Smith, E. E., \& Medin, D. L. (1981). Categories and concepts. Cambridge, MA: Harvard University Press.

SMITH, L. C. (1984). Semantic satiation affects category membership decision time but not lexical priming. Memory \& Cognition, 12, 483-488.

SMiTH, L. [C.], \& KleIN, R. (1990). Evidence for semantic satiation: Repeating a category slows subsequent semantic processing. Journal of Experimental Psychology: Learning. Memory. \& Cognition, 16, 852-861.

Tabossi, P., Colombo, L., \& Job, R. (1987). Accessing lexical ambiguity: Effects of context and dominance. Psychological Research, 49 $161-167$.

Taylor, M. M., \& Henning, G. B. (1963). Verbal transformation and an effect of instructional bias on perception. Canadian Journal of Psychology, 17, 210-223.
Trtchener, E. B. (1915). A beginner's psychology. New York: MacMillan.

WARREN, R. M. (1961). Illusory changes of distinct speech upon repetition-The verbal transformation effect. British Journal of Psychology, 52, 249-258.

WARREN, R. M. (1968). Verbal transformation effect and auditory perceptual mechanisms. Psychological Bulletin, 70, 261-270.

WARREN, R. M., \& GREGORY R. L. (1958). An auditory analogue of the visual reversible figure. American Journal of Psychology, 71, 612-613.

\section{NOTE}

I. In this article, the term "acoustic adaptation" refers to an auditory level of speech processing. In contrast, the term "phonetic adaptation" is loosely applied to a more abstract level of representation of speech sounds.

APPENDIX A

Stimulus Materials

\begin{tabular}{|c|c|c|c|c|c|}
\hline $\begin{array}{c}\text { Category } \\
\text { Name }\end{array}$ & $\begin{array}{c}\text { Primed } \\
\text { Trial }\end{array}$ & $\begin{array}{c}\text { Unprimed } \\
\text { Trial }\end{array}$ & $\begin{array}{l}\text { Filler } \\
\text { Trial }\end{array}$ & $\begin{array}{l}\text { Filler } \\
\text { Trial }\end{array}$ & $\begin{array}{l}\text { Filler } \\
\text { Trial }\end{array}$ \\
\hline Time & minute-hour & iron-copper & year-Tokyo & Alaska-prune & gold-coast \\
\hline Metal & iron-copper & minute-hour & brass-thunder & lettuce-brandy & feather-bed \\
\hline Gem & ruby-diamond & apple-pear & emerald-rug & jet-pillow & chili-powder \\
\hline Fruit & apple-pear & ruby-diamond & peach-jade & Cuba-lace & piano-player \\
\hline Dog & collie-poodle & jazz-blues & beagle-month & sage-steel & china-closet \\
\hline Music & jazz-blues & collie-poodle & folk-satin & rayon-yard & mosquito-bite \\
\hline Cloth & wool-cotton & hammer-wrench & silk-week & saimon-bomb & yellow-pages \\
\hline Tool & hammer-wrench & wool-cotton & drill-pink & crow-taxi & clam-chowder \\
\hline Fuel & oil-coal & python-cobra & gas-sword & spider-melon & hockey-puck \\
\hline Srake & python-cobra & oil-coal & iper-orchid & lily-flannel & pine-scent \\
\hline Color & & penny-dime & reen-ro & jeep-dagger & ice-pick \\
\hline Money & penny-dime & red-blue & dollar-olive & wagon-waltz & brown-sugar \\
\hline Liquor & rum-gin & Mars-Pluto & odka-eagle & terrier-nyl & onion-ring \\
\hline Planet & Mars-Pluto & rum-gin & Venus-salt & flute-parsley & squash-court \\
\hline Flower & tulip-ro & shrimp & daisy-beer & stereo-bronze & bullet-hole \\
\hline Seafood & shrimp- & & yster-rugby & bench-iris & opera-glasses \\
\hline Country & Mexico-Spain & chair-sofa & Germany-pliers & lemon-rock & bicycle-path \\
\hline Furniture & chair-sofa & Mexico-Spain & desk-wine & grape-shark & sun-hat \\
\hline Crime & murder- & maple- & fraud $-c$ & plum-Dallas & duck-call \\
\hline & aple-oak & lurder-rape & willow-train & pearl-felony & scarlet--fever \\
\hline Fish & trout-tuna & car-truck & guppy-wind & tango-berry & mint-tea \\
\hline Vehicle & r-truck & tuna & -violet & mango-ruler & black-cye \\
\hline Weapon & gun-rifle & flea-ro & pistol-lime & herb-cyclone & ginger-ale \\
\hline Insect & flea-roach & gun-rifle & bee-baseball & century-boa & storm-door \\
\hline Weather & rain-snow & pepper-paprika & hail-peso & boat-silver & baby-rattle \\
\hline & pepper-paprika & & garlic-softball & whale-polo & crab-cake \\
\hline Sport & soccer-golf & robin-owl & football-van & celery-fog & kerosene-lamp \\
\hline Bird & robin owl & soccer-golf & sparrow-ruble & stove-topaz & love-seat \\
\hline City & Paris-London & carrot-pea & Madrid-sodium & cherry dice & white-sauce \\
\hline Vegetable & carrot-pea & Paris-London & spinach-mohair & stool-quartz & table-tennis \\
\hline
\end{tabular}


APPENDIX B

Mean Log Response Latencies and Standard Deviations as a Function of Number of Repetitions ( 3 or 30), Prime-Target Relation, and Speaker

\begin{tabular}{|c|c|c|c|c|c|}
\hline \multirow[b]{3}{*}{ Decision } & \multirow{3}{*}{$\begin{array}{l}\text { Prime-Target } \\
\text { Relationship }\end{array}$} & \multicolumn{4}{|c|}{ Latency } \\
\hline & & \multicolumn{2}{|c|}{3} & \multicolumn{2}{|c|}{30} \\
\hline & & $M$ & $S D$ & $M$ & $S D$ \\
\hline \multicolumn{6}{|c|}{ Single-Speaker Condition } \\
\hline Yes & Both members & 3.172 & .06 & 3.185 & .06 \\
\hline Yes & $\begin{array}{l}\text { FLOWER: rose-tulip } \\
\text { No member } \\
\text { FLOWER: shrimp-lobster }\end{array}$ & 3.188 & .05 & 3.191 & .05 \\
\hline No & $\begin{array}{l}\text { One member } \\
\text { FLOWER: daisy-beer }\end{array}$ & 3.233 & .05 & 3.230 & .05 \\
\hline No & $\begin{array}{l}\text { No member } \\
\text { FLOWER: stereo-bronze }\end{array}$ & 3.245 & .05 & 3.244 & .05 \\
\hline No & $\begin{array}{l}\text { No member associated } \\
\text { FLOWER: bullet-hole }\end{array}$ & 3.230 & .05 & 3.228 & .05 \\
\hline \multicolumn{6}{|c|}{ Multiple-Speaker Condition } \\
\hline Yes & $\begin{array}{l}\text { Both members } \\
\text { FLOWER: rose-tulip }\end{array}$ & 3.189 & .04 & 3.190 & .04 \\
\hline Yes & $\begin{array}{l}\text { No member } \\
\text { FLowER: shrimp-lobster }\end{array}$ & 3.208 & .04 & 3.206 & .04 \\
\hline No & $\begin{array}{l}\text { One member } \\
\text { FLOWER: daisy-beer }\end{array}$ & 3.248 & .03 & 3.246 & .03 \\
\hline No & $\begin{array}{l}\text { No member } \\
\text { FLOWER: stereo-bronze }\end{array}$ & 3.262 & .03 & 3.255 & .03 \\
\hline No & $\begin{array}{l}\text { No member associated } \\
\text { FLOWER: bullet-hole }\end{array}$ & 3.245 & .04 & 3.239 & .04 \\
\hline
\end{tabular}

(Manuscript received February 15, 1996; accepted for publication April 23, 1996.) 